\title{
Specialty Grand Challenge: Water and the Built Environment
}

\author{
Auroop Ratan Ganguly* and Ruth Linnaea Cahill \\ Sustainability \& Data Sciences Laboratory, Department of Civil \& Environmental Engineering, Northeastern University, Boston, \\ MA, United States
}

Keywords: water infrastructure, wastewater systems, lifeline networks, climate change, population change, regional adaptation, hydrological extremes, food-energy-water

\section{INTRODUCTION}

Most ancient civilizations were built around water bodies to ensure a steady supply of freshwater. Ranging from intricate irrigation networks and dams in Mesopotamia and Egypt, to sophisticated water supply and sanitation systems in the Indus Valley and Angkor Thom, water and the built infrastructures have been tightly coupled with each other since antiquity. This tradition, born out of necessity, has continued through the Middle Ages in the civilizations of Southeast Asia and the Middle East through Renaissance-era Europe, to modern times (Angelakis et al., 2018). However, despite millennia of experience, major knowledge-gaps and execution challenges remain in the relevant sciences, engineering, and policy principles.

Water distribution systems in cities across the world still report severe losses of precious drinking water resources in transit, contamination of drinking water during natural hazards, as well as unhygienic water treatment and sanitation practices, especially in developing economies. Cyclones and storm surge overwhelm dams and levees even in developed nations, while reservoirs and water retention practices prove inadequate in face of severe droughts, leading to food scarcity and energy insecurity across large parts of the globe. Stresses from climate or land use change and population growth or movement, silt and sediment deposit in surface waters and over pumping of groundwater, as well as shocks from exacerbating weather and hydrological extremes, combined with aging assets and infrastructure, continue to degrade water and sanitation service levels across multiple sectors.

According to the United Nations (UN), around $95 \%$ of all disasters globally are related to excess or deficit of water. In the period from 1995 to 2015, floods impacted 2.3 billion people worldwide, killed 157,000, and resulted in US $\$ 662$ billion in damage, while the corresponding figures for droughts were 1.1 billion, 22,000 and US\$100 billion (UNISDR, 2015). A 2018 UN report suggested that, globally, floods and droughts affected over 35 million and over 9 million people, respectively. The World Health Organization (WHO) estimates that more than $35 \%$ of the world's population lacks basic sanitation while about $11 \%$ do not have access to adequate water sources. Improved water, sanitation, and hygiene can prevent $9.1 \%$ of all diseases and $6.3 \%$ of all deaths worldwide (Prüss-Üstün et al., 2008; WHO and UNICEF, 2012). Furthermore, per the UN, " 3 in 10 people lack access to safely managed drinking water services and 6 in 10 people lack access to safely managed sanitation facilities," "water scarcity affects more than 40 per cent of the global population" and "each day, nearly 1,000 children die due to preventable water and sanitation-related diarrheal diseases." This dire situation is exacerbated by degrading, inadequate, or even non-existent built infrastructures associated with water. 
Our understanding of water and the built environment, along with our ability to design, manage, operate and maintain water related infrastructures, have benefited from lessons learned over millennia. Nevertheless, this interdisciplinary area continues to represent a grand societal priority that needs to be urgently addressed by researchers and practitioners (Sedlak, 2019).

\section{WATER AND THE BUILT ENVIRONMENT Water Sector Infrastructure Functions}

The American Society of Civil Engineers lists five types of infrastructures related to water, grouped by functions: (a) drinking water, (b) wastewater, (c) dams, (d) levees, and (e) inland waterways. The US National Academy of Engineering (NAE) lists 14 grand challenges, one of which is to "provide access to clean water." The infrastructure challenges associated with water may be grouped into three functional categories: drinking water and sanitation, resilience to water extremes, and the food-energy-water nexus.

\section{Drinking Water and Sanitation}

The United Nations (UN) lists 17 Sustainable Development Goals (SDGs), one of which deals exclusively with clean water and sanitation. According to the SDG 6, "over 1.7 billion people are currently living in river basins where water use exceeds recharge" while "2.4 billion people lack access to basic sanitation services, such as toilets or latrines." The United States (US) National Academy of Engineering (NAE) lists 14 grand engineering challenges, one of which is to provide access to clean water. Ensuring a supply of drinking water is critically dependent on water distribution systems, while providing safe sanitation is dependent on sewer systems. Our ability to assure water security and associated public health during shocks and stresses is dependent on interdependent critical lifelines that affect and are in turn affected by infrastructures directly or indirectly related to water.

Water Distribution Systems (WDS), comprising "pipes, pumps, valves, storage tanks, reservoirs, meters, fittings, and other hydraulic appurtenance" (NRC, 2006), transport potable water to taps from public water treatment plants or wells. WDS alone span about a million miles in the US. Water losses in urban WDS globally can vary from $5 \%$ in cities like Singapore to nearly 95\% in Lagos, Nigeria. Lead and copper contamination can result from old pipes and fixtures. While developing countries are particularly prone, the lead contamination from water service lines of drinking water in Flint, Michigan (Olson et al., 2017), is a reminder of the vulnerabilities even in the world's largest economies.

Sewers and sanitary systems drainage and treatment include sewage and storm water infrastructure, as well as industrial drainage and sewer treatment plants. The UN SDG 6 has the stated desire "to ensure the availability and sustainable management of water and sanitation for all." However, 892 million people practice open defecation while 2.4 billion lack access to basic sanitation facilities such as toilets or latrines, and $80 \%$ of the wastewater from human activities is discharged into water bodies without any treatment. Sewage has been used as an indicator of population health (Carey, 2019). The US alone has 14,748 wastewater treatment plants and 1,300,000 miles of sewer lines, servicing $76 \%$ of the population, and the demand for centralized wastewater treatment is expected to rise by $23 \%$ by 2032. However, the ASCE Infrastructure Report Card cited earlier gave America's wastewater infrastructure an overall rating of $\mathrm{D}+$ in 2017.

\section{Resilience to Water Extremes}

Water-related hazards, particularly floods and droughts, cause loss of human lives and misery. Resilience to hazards requires robustness to perturbations, management of consequences, and efficient recovery of essential services. Consequence management, maintenance and recovery of essential services require a focus on interconnected lifeline networks: transport, communications, public health, power, and water or wastewater.

Dams, levees, dikes and seawalls protect against riverine floods and coastal storm surge, while reservoirs, desalination plants and rainwater retention infrastructures reduce or mitigate the possibility of droughts. Storm water drainage systems are designed to prevent urban floods. Globally there are claims that 57,000 large and 300 major dams exist, and the ASCE Infrastructure Report Card mentions that the US alone has 90,580 dams with an average age of 56 years. Furthermore, the US has a nationwide network of 30,000 documented miles of levees. The massive destruction to the city of New Orleans triggered by Hurricane Katrina in 2005 was ultimately caused by the breach of a levee which was known to be in dire need of repair and maintenance.

Protective infrastructures include natural or green infrastructure systems, such as restored wetlands and riverbanks in urban or rural regions, as well as mangroves and oyster beds which can alleviate storm surge in coastal areas. Integration of manmade gray infrastructures with nature-based green infrastructures has been proposed to achieve greater resilience and sustainability (Liu and Jensen, 2018).

An important consideration for resilience is the interdependence of lifeline infrastructure networks such as power-communication-transportation-water across multiple scales (e.g., see Ganguly et al., 2018a; NIAC, 2018). Thus, water distribution systems, specifically operations of pumps, are impacted by the operations of the power grid, which in turn may have a two-way feedback with communications networks. Under extreme water shortages, water in tanks or bottled water may need to be transported through multimodal logistics networks.

\section{Food-Energy-Water Nexus}

Water and associated infrastructure are intimately connected with the food and energy sectors (Romero-Lankao et al., 2017). The water-food nexus is enabled by irrigation infrastructures along with drought prevention and water retaining infrastructures ranging from reservoirs to rainwater harvesting structures. The water-energy nexus includes infrastructures for energy production, storage and distribution or transmission, which collectively consume significant volumes of water, as well as water and wastewater infrastructure that require electricity to operate. 


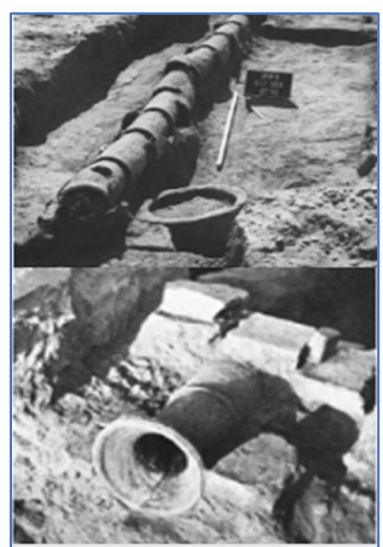

A

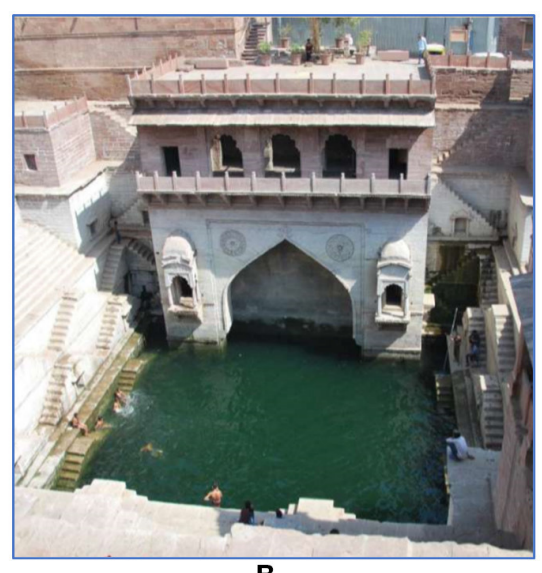

B

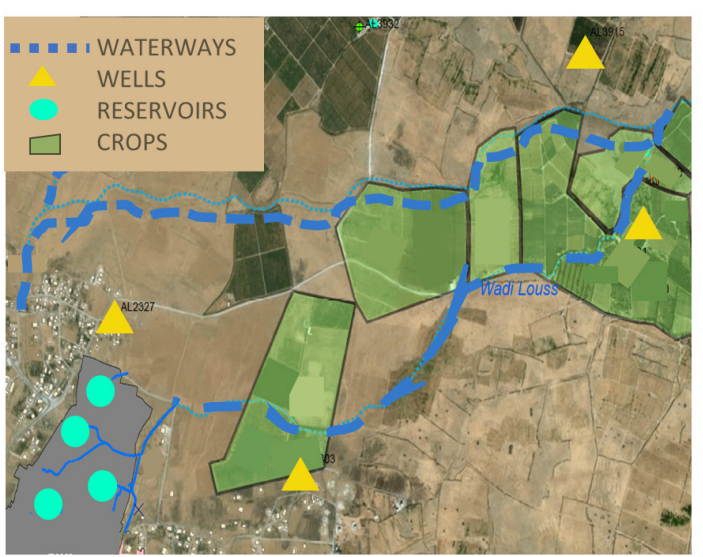

C
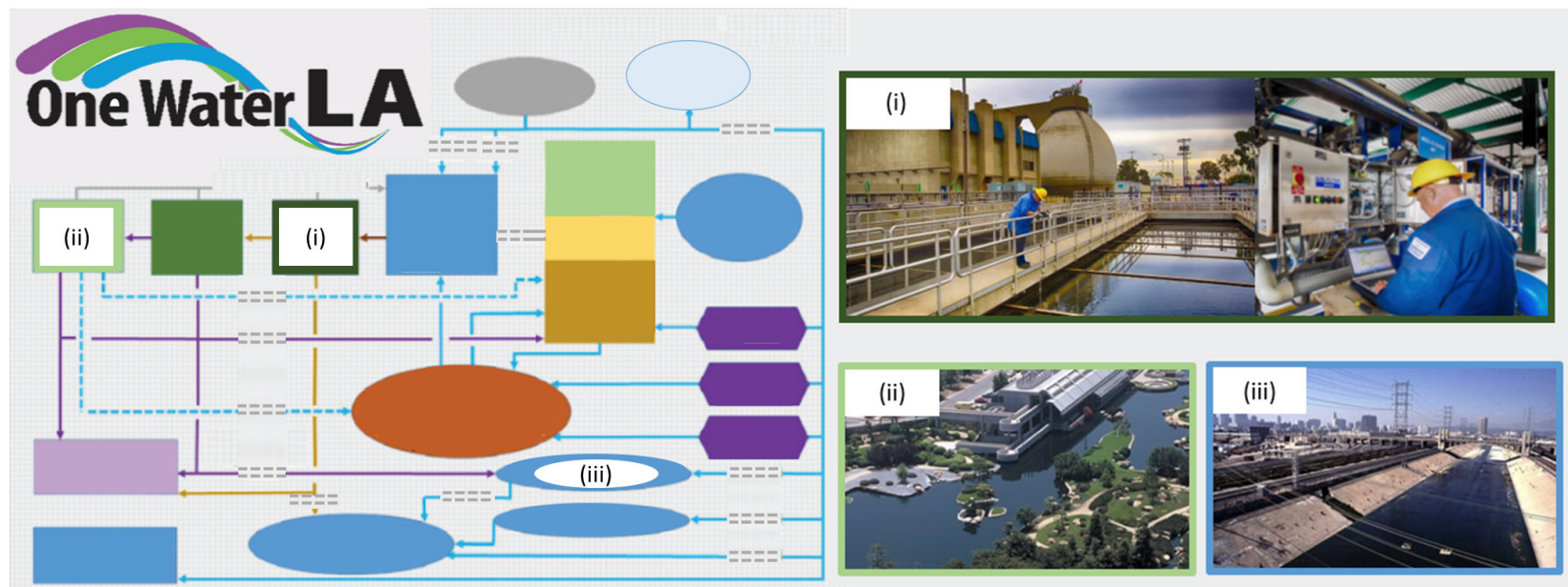

D

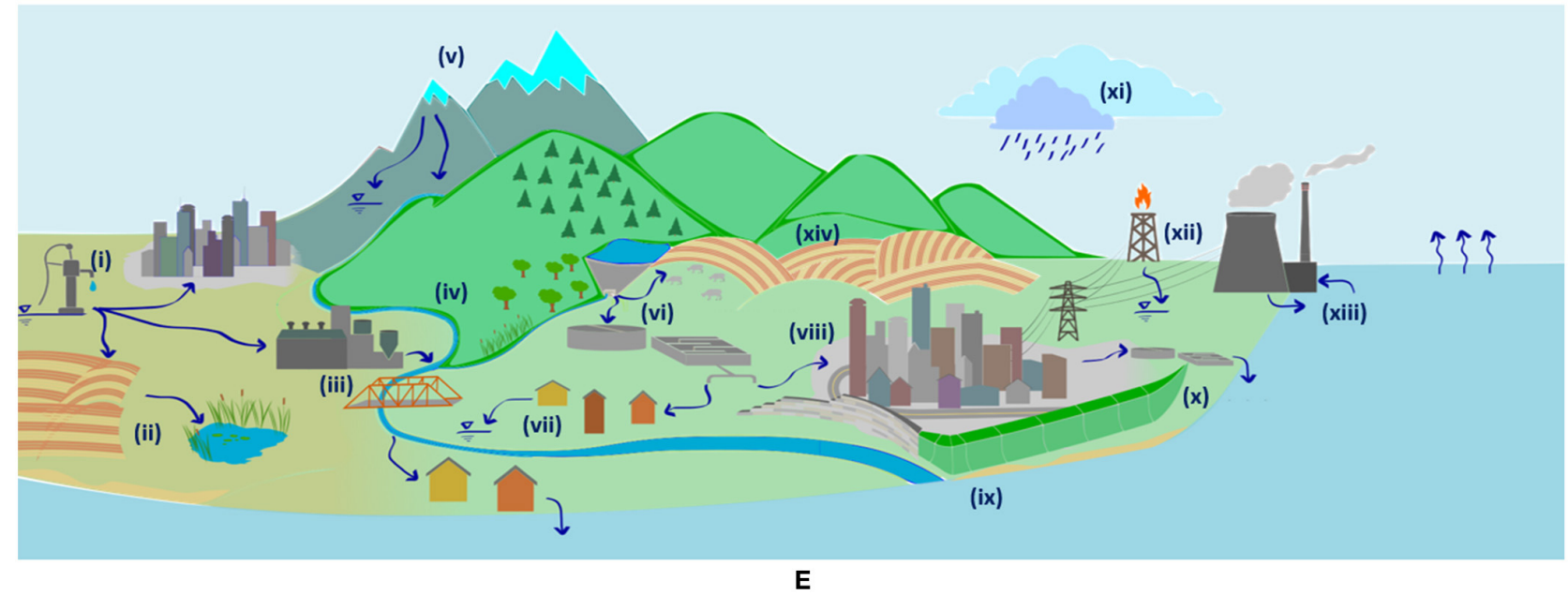

FIGURE 1 | Water infrastructure through millennia with lessons learned for modern times. The evolution of water and built environment throughout human history, along with current and anticipated changes in both the water cycle across scales as well as the coupled natural-engineered-human systems, can offer perspectives relevant to the design and operations of infrastructures related to water. The top layer shows sewerage pipes in ancient (4th to 3rd century BCE) Mesopotamia (Antoniou et al., 2016; figure courtesy, Andreas Angelakis and Saifullah Khan) (A), the stepwell of Toorji (Toorii ka Jhalra) built in 1740 CE by the Queen of Jodhpur, Rajasthan, India (photo courtesy, Udit Bhatia) (B) and the rainfall-runoff water harvesting and storage systems constructed by Nabateans and Romans and maintained from the 1st to the 21st century CE in the Umm el-Jimal archaeological site near Mafraq, Jordan which sustained the sedentary and nomadic populations of the region

(Continued) 
FIGURE 1 | (adapted from figure by Bert de Vries and Kyle Egerer) (C). In the Mafraq region of Jordan (C), plans are being developed (Maxmen, 2017) to reactivate ancient water infrastructures to manage large water deficits caused by changes in demand (owing to unregulated over-pumping for use in municipal and agricultural sectors exacerbated by population growth and migration) and supply (owing to rapid depletion of deep fossil and slow recharging aquifers and changes in the hydrological cycle). The middle layer shows a modern urban water system exemplified by the AAEES 2019 Honor Award-winning One Water LA Dashboard (D), a schematic of which is shown (adapted from image courtesy, Azya Jackson and colleagues at LA Water). This collaborative decision support tool (Blair, 2016) allows Los Angeles (LA: California, USA) city departments to monitor and manage all aspects of urban water, including wastewater (i), drinking water (ii) and water bodies such as the LA river (iii). The bottom layer depicts the current and future challenges of the water and built environment, especially in view of changes to the natural water cycle and the built and human systems as well as in corresponding stresses and threat multipliers (E). The schematic shows that water collection infrastructure from groundwater (i) and surface water (vi) are impacted by changes in precipitation (xi), along with sinks such as glaciers (v); water use in agriculture (iv), residential and industrial areas (xiv, viii, iii) impact water quantify and demand; while water pollution from runoff (ii, iii, vii, xii) and treatment capacity (vi) impact water quality. Climate attributable changes in the statistics of weather or hydrological extremes, along with increases in sea water temperatures and sea level rise, impact critical infrastructures such as those designed for energy production (xiii) and flood protection (ix, $\mathbf{x}$ ).

Hydroelectric and tidal power plants directly convert water pressure into electricity, and all thermoelectric power plants including those driven by nuclear and other renewables or by fossil fuels require water for cooling (Ganguli et al., 2017). In the agricultural sector, irrigation and water-retention infrastructures along with groundwater extraction systems are important for food production, while food transportation and preservation rely on multimodal transportation and storage infrastructures. Transportation modes include road, rail, air, maritime or inland waterways and associated infrastructures.

In the US, about $45 \%$ of all freshwater withdrawal is used for thermoelectric energy production and 32\% is used for irrigation, while across the globe the usage is about 69, 23, and $7 \%$ across agriculture, energy and municipal sectors, respectively. Globally, FAO AQUASAT lists four types of irrigation technologies, specifically surface irrigation, sprinkler irrigation, localized irrigation and spate irrigation, representing various levels of efficiency, control and mechanization.

\section{CALL FOR RESEARCH}

Water infrastructures need to be resilient and must adapt to change, which in turn require an understanding of change drivers and (potentially compound) extremes (e.g., Luthy et al., 2020). Traditional and modern tools, ranging from sensors, embedded systems and Internet of Things (IoTs) to computational analytics, robotics and Artificial Intelligence (AI), must be brought to bear to develop and leverage scientific insights and engineering principles in a way that can inform policy.

One important research area is water infrastructures in the context of sustainability and resilience (Thacker et al., 2019). First, design of hydraulic infrastructures such as dams and levees, natural-built systems (Sutton-Grier et al., 2015), networked systems such as water distribution and irrigation networks, as well as coupled systems such as water and power networks, must be robust and cost-effective (Aerts et al., 2014). Second, operations and maintenance, as well as plans for post-damage recovery, are essential for continuity of essential services or functions. Third, there is a need to efficiently design and operate, as well as repair or reinforce, in a way that adapts to change and can be continuously monitored.
A second area of research (see Moss et al., 2019) includes the development and adaptation of state-of-the-art and emerging tools and methods for water infrastructures. Advances in remote and in-situ sensor systems offer new ways for continuous monitoring and damage mitigation. AI, including autonomous robots and data-driven sciences including machine learning, can detect leaks in water pipes or sewer networks (Gong et al., 2016), monitor the food supply chain, regulate the smart grid, and dynamically inform emergency managers or planners. Network science, machine learning, and optimization methods can help develop predictive understanding of lifeline systems leading to informed strategies for robustness and recovery (Giustolisi et al., 2019; Yadav et al., 2020). Computational simulation models ranging from physics-based numerical models of environmental and climate systems to agent-based models of social, economic and behavioral systems provide new understanding. Geographical information sciences and systems, sensor-based systems, as well as citizen science, offer new ways to gather, process, analyze and present information. Developments in probabilistic risk analysis, system dynamics, optimization methods, social dynamics and policy offer the ability to translate the science to stakeholder needs and to informed decision tools and policy aids across geographic scales and disparate regions over multiple time horizons.

Finally, a time-critical research area is advancing predictive understanding of change drivers and their impacts, along with translating the understanding and predictions (or projections) to novel insights and risk-informed design and decision principles (Milly et al., 2008, 2015). Population growth and movement, climate and land use change, as well as lifestyle aspirations and interconnected economies, are causing enormous stresses on local to regional water resources (Vörösmarty et al., 2010) and built infrastructures related to water. This has been compounded by decaying infrastructures, across all economies. The translation to action requires not just strengthening our scientific understanding and engineering principles (e.g., changes in precipitation design curves: Kao and Ganguly, 2011) but also putting in place the necessary economic interventions, financial incentives, and resources prioritizations (Ganguly et al., 2018b). Private-public sector partnerships with academic and/or government research organizations would be important to translate to decisions and policy. 
Figure 1 attempts to depict the essence of this grand challenge. Lessons learned from historical and current water infrastructures, along with an understanding of the relationship of the water and built environment with the Earth's ever-changing water cycle-in the context of the coupled natural-engineered-human ecosystems within which they reside-pave the way for the design, operations, retrofitting and maintenance of resilient and sustainable water infrastructure of the future.

\section{AUTHOR CONTRIBUTIONS}

ARG conceptualized and wrote the first version of the paper. RLC developed Figure 1 with suggestions from ARG and contributions from the collaborators as acknowledged. ARG and RLC collaborated on the final version of the paper. All authors contributed to the article and approved the submitted version.

\section{FUNDING}

Funding was provided by the US National Science Foundation's INQUIRE (NSF Award Number 1735505), BIGDATA (1447587), and Cyber SEES (1442728) awards.

\section{REFERENCES}

Aerts, J. C., Botzen, W. W., Emanuel, K., Lin, N., De Moel, H., and Michel-Kerjan, E. O. (2014). Evaluating flood resilience strategies for coastal megacities. Science 344, 473-475. doi: 10.1126/science. 1248222

Angelakis, A. N., Asano, T., Bahri, A., Jimenez, B. E., and Tchobanoglous, G. (2018). Water reuse: from ancient to modern times and the future. Front. Environ. Sci. 6:26. doi: 10.3389/fenvs.2018.00026

Antoniou, G. P., De Feo, G., Fardin, F., Tamburrino, A., Khan, S., Tie, F., et al. (2016). Evolution of toilets worldwide through the millennia. Sustainability 8:779. doi: 10.3390/su8080779

Blair, S. (2016). Los Angeles Aims to Unify a Complex Water Infrastructure. Engineering News-Record, November 2. Available online at: https:// www.enr.com/articles/40845-los-angeles-aims-to- unify-a-complex-waterinfrastructure

Carey, J. (2019). News Feature: Interested in gauging a population's health? Look to sewage. Proc. Natl. Acad. Sci. U.S.A. 116, 5836-5839. doi: 10.1073/pnas.1903138116

Ganguli, P., Kumar, D., and Ganguly, A. R. (2017). US power production at risk from water stress in a changing climate. Scient. Rep. Nat. Publish. Group 7:11983. doi: 10.1038/s41598-017-12133-9

Ganguly, A. R., Bhatia, U., and Flynn, S. (2018a). Critical Infrastructures Resilience: Policy and Engineering Principles. Routledge: Taylor \& Francis, 131. doi: 10.4324/9781315153049

Ganguly, A. R., Kodra, E., Bhatia, U., Warner, M. E., Duffy, K., Banerjee, A., et al. (2018b). Data-Driven Solutions. Climate 2020: Degrees of Devastation, 82-85. United Nations Association of the United Kingdom (UNA-UK). Available online at: https://www.climate2020.org.uk/data-driven-solutions/

Giustolisi, O., Ridolfi, L., and Simone, A. (2019). Tailoring centrality metrics for water distribution networks. Water Resour. Res. 55, 2348-2369. doi: 10.1029/2018WR023966

Gong, W., Suresh, M. A., Smith, L., Ostfeld, A., Stoleru, R., Rasekh, A., et al. (2016). Mobile sensor networks for optimal leak and backflow detection and localization in municipal water networks. Environ. Model. Softw. 80, 306-321. doi: 10.1016/j.envsoft.2016.02.001

Kao, S. C., and Ganguly, A. R. (2011). Intensity, duration, and frequency of precipitation extremes under 21st-century warming scenarios. J. Geophys. Res. Atmosph. 116:D16. doi: 10.1029/2010JD015529

\section{ACKNOWLEDGMENTS}

Logistical support was provided by Northeastern University's Office of the Provost, College of Engineering; and the Khoury College of Computer Science. The authors are grateful for helpful discussions with current and former students at Northeastern University (NU) Sustainability and Data Sciences Laboratory (SDS Lab), specifically, former PhD students Udit Bhatia of the Indian Institute of Technology at Gandhinagar; and Evan Kodra, CEO of Cambridge, MA, USA, based startup risQ; as well as NU SDS Lab PhD students Kate Duffy and Nishant Yadav; besides undergraduate student researcher Violet Lingenfelter. Figure 1 is based on contributions from the following collaborators (in alphabetical order by last name): Andreas Angelakis of the Agricultural Research Institute of Crete in Greece; Udit Bhatia (see above), Bert de Vries of Calvin University in Michigan, USA, who is director of the Umm el-Jimal Archaeological Project in Jordan and Kyle Egerer of DHI WASY, Bremen, Germany; Azya Jackson, along with Ali Poosti, Adel Hagekhalil and Lenise Marrero, of LA Water in Los Angeles, CA, USA; Saifullah Khan of Bahauddin Zakariya University in Multan, Pakistan; as well as Dhrubajyoti Sen of the Indian Institute of Technology Kharagpur in West Bengal, India.

Liu, L., and Jensen, M. B. (2018). Green infrastructure for sustainable urban water management: practices of five forerunner cities. Cities 74, 126-133. doi: 10.1016/j.cities.2017.11.013

Luthy, R. G., Wolfand, J. M., and Bradshaw, J. L. (2020). Urban water revolution: sustainable water futures for california cities. J. Environ. Eng. Am. Soc. Civil Engin. 146:04020065. doi: 10.1061/(ASCE)EE.1943-7870.0001715

Maxmen, A. (2017). Jordan seeks to become an oasis of water-saving technology. Nat. News 549, 142-143. doi: 10.1038/549142a

Milly, P., Betancourt, J., Falkenmark, M., Hirsch, R., Kundzewicz, Z., Lettenmaier, D., et al. (2008). Stationarity is dead: whither water management? Science 319, 573-574. doi: 10.1126/science.1151915

Milly, P. C., Betancourt, J., Falkenmark, M., Hirsch, R. M., Kundzewicz, Z. W., Lettenmaier, D. P., et al. (2015). On critiques of "Stationarity is dead: Whither water management?" Water Resour. Res. 51, 7785-7789. doi: 10.1002/2015WR017408

Moss, R. H., Avery, S., Baja, K., Burkett, M., Chischilly, A. M., Dell, J., et al. (2019). Evaluating knowledge to support climate action: a framework for sustained assessment. Report of an independent advisory committee on applied climate assessment. Weather Clim. Soc. 11, 465-487. doi: 10.1175/WCAS-D-18-0134.1

NIAC. (2018). Water Sector Resilience: Final Report and Recommendations. National Infrastructure Advisory Council, 206. Available online at: https:// www.cisa.gov/sites/default/files/publications/niac-water-resilience-finalreport-508.pdf

NRC. (2006). Drinking Water Distribution Systems: Assessing and Reducing Risks. Washington, DC: The National Academies Press. National Research Council, 404 pages.

Olson, T. M., Wax, M., Yonts, J., Heidecorn, K., Haig, S. J., Yeoman, D., et al. (2017). Forensic estimates of lead release from lead service lines during the water crisis in Flint, Michigan. Environ. Sci. Technol. Lett. 4, 356-361. doi: 10.1021/acs.estlett.7b00226

Prüss-Üstün, A., Bos, R., Gore, F., and Bartram, J. (2008). Safer Water, Better Health: Costs, Benefits and Sustainability of Interventions to Protect and Promote Health. Geneva: World Health Organization, 60. CDC Summary. Available online at: https://www.cdc.gov/healthywater/global/wash_statistics. html; http://whqlibdoc.who.int/publications/2008/9789241596435_eng.pdf

Romero-Lankao, P., McPhearson, T., and Davidson, D. J. (2017). The foodenergy-water nexus and urban complexity. Nat. Climate Change 7, 233-235. doi: $10.1038 /$ nclimate 3260 
Sedlak, D. (2019). How Development of America's Water Infrastructure Has Lurched Through History. Pew Trend Magazine. Available online at: https:// www.pewtrusts.org/en/trend/archive/spring-2019/how-development- ofamericas-water-infrastructure-has-lurched-through-history

Sutton-Grier, A. E., Wowk, K., and Bamford, H. (2015). Future of our coasts: the potential for natural and hybrid infrastructure to enhance the resilience of our coastal communities, economies and ecosystems. Environ. Sci. Policy 51, 137-148. doi: 10.1016/j.envsci.2015. 04.006

Thacker, S., Adshead, D., Fay, M., Hallegatte, S., Harvey, M., Meller, H., et al. (2019). Infrastructure for sustainable development. Nat. Sust. 2, 324-331. doi: 10.1038/s41893-019-0256-8

UNISDR. (2015). The Human Cost of Weather-Related Disasters. 1995-2015. Center for Research on the Epidemiology of Disasters (CRED) The United Nations Office for Disaster Risk Reduction, 30. Available online at: https://reliefweb.int/sites/reliefweb.int/files/resources/COP21_ WeatherDisastersReport_2015_FINAL.pdf

Vörösmarty, C. J., McIntyre, P. B., Gessner, M. O., Dudgeon, D., Prusevich, A., Green, P., et al. (2010). Global threats to human water security and river biodiversity. Nature 467, 555-561. doi: 10.1038/nature09440
WHO and UNICEF. (2012). Progress on Drinking Water and Sanitation: 2012 Update. WHO/UNICEF Joint Monitoring Programme for Water Supply and Sanitation. World Health Organization. CDC Summary. Available online at: https://www.cdc.gov/healthywater/global/wash_statistics.html; https:// reliefweb.int/sites/reliefweb.int/files/resources/JMPreport2012.pdf.

Yadav, N., Chatterjee, S., and Ganguly, A. R. (2020). Resilience of urban transport network-of-networks under intense flood hazards exacerbated by targeted attacks. Scient. Rep. Nat. Publish. Group 10:10350. doi: 10.1038/s41598-020-66 $049-\mathrm{y}$

Conflict of Interest: The authors declare that the research was conducted in the absence of any commercial or financial relationships that could be construed as a potential conflict of interest.

Copyright $\odot 2020$ Ganguly and Cahill. This is an open-access article distributed under the terms of the Creative Commons Attribution License (CC BY). The use, distribution or reproduction in other forums is permitted, provided the original author(s) and the copyright owner(s) are credited and that the original publication in this journal is cited, in accordance with accepted academic practice. No use, distribution or reproduction is permitted which does not comply with these terms. 